(c) American Dairy Science Association, 2004.

\title{
Pharmacokinetics of Marbofloxacin in Lactating Cows After Repeated Intramuscular Administrations and Pharmacodynamics Against Mastitis Isolated Strains
}

\author{
M. Schneider, M. Vallé, F. Woehrlé, and B. Boisramé \\ Vétoquinol, R\&D Department, B.P. 189, 70204 Lure, France
}

\begin{abstract}
The plasma and milk pharmacokinetics of marbofloxacin, a fluoroquinolone antibacterial compound, were evaluated in dairy cows, as well as its pharmacodynamic characteristics against mastitis-isolated pathogens. Marbofloxacin was given intramuscularly as a $10 \%$ aqueous solution to dairy cows either at a single dose or at repeated doses of $2 \mathrm{mg} / \mathrm{kg}$ once daily for $3 \mathrm{~d}$. Blood and milk samples were collected for the determination of the concentration of marbofloxacin and of its putative metabolites: N-desmethyl-marbofloxacin and N-oxide-marbofloxacin. Bacterial field isolates were from milk samples collected from dairy cows suspected of having an intramammary infection. After identification, the minimal inhibitory concentration (MIC) was determined against the isolated strains. The maximal marbofloxacin concentration $\left(\mathrm{C}_{\max }\right)_{\text {ob- }}$ served in milk after the first administration was 1.024 $\mu \mathrm{g} / \mathrm{mL}$, and the area under the curve during the first dosing interval was $6.513 \mu \mathrm{g} / \mathrm{h}$ per milliliter. After the third administration, these parameters were slightly increased (about $20 \%$ at most). Both metabolites were detected in the milk, but their concentrations were below the limit of quantification. The MIC against $90 \%$ of the population $\left(\mathrm{MIC}_{90}\right.$ ) of Escherichia coli was 0.016 $\mu \mathrm{g} / \mathrm{mL}$, and it was $0.229 \mu \mathrm{g} / \mathrm{mL}$ against Staphylococcus aureus. The following surrogate clinical outcome markers were obtained against $E$. coli strains: a $\mathrm{C}_{\max } / \mathrm{MIC}$ ratio of 67 and an area under the curve/MIC ratio of $407 \mathrm{~h}$. Hence, a possible efficacy of marbofloxacin in the treatment of $E$. coli-induced mastitis could be expected as the endpoints of 10 and $250 \mathrm{~h}$, respectively, are reached.
\end{abstract}

(Key words: marbofloxacin, pharmacokinetics, pharmacodynamics, surrogate marker)

Abbreviation key: AUC = area under the curve, $\mathbf{A U C} \mathbf{C}_{\text {last }}=$ area under the concentration-time curve un-

Received March 15, 2003.

Accepted May 2, 2003.

Corresponding author: M. Schneider; e-mail: marc.Schneider@ vetoquinol.com. til the last measurable time point, $\mathbf{C}_{\mathbf{m a x}}=$ maximum concentration, $\mathbf{C}_{\max } \mathbf{1}^{\text {st }} \mathbf{o b s}=\mathrm{C}_{\max }$ observed after the first administration, $\mathbf{C}_{\max } 3^{\text {rd }}$ obs $=\mathrm{C}_{\max }$ observed after the third administration, $\mathbf{L O Q}=$ limit of quantification, $\mathbf{M B C}=$ minimum bactericidal concentration, $\mathbf{M I C}=$ minimum inhibitory concentration, $\mathbf{M I C}_{50}=$ concentration of antibiotic able to inhibit the visible growth of $50 \%$ of a population of microorganisms, $\mathbf{M I C}_{\mathbf{9 0}}=$ concentration of antibiotic able to inhibit the visible growth of $90 \%$ of a population of microorganisms, $\mathbf{M R T}_{\text {last }}=$ mean residence time till the last measurable time point, $\mathbf{T}_{\max }=$ occurrence time of the maximum plasma concentration, $\mathbf{T}_{1 / 2 \mathbf{K} 01}=$ absorption half-life, $\mathbf{T}_{1 / 2 \lambda \mathbf{z} 1 \mathbf{s t}}=$ elimination half-life after the first administration, $\mathbf{T}_{1 / 2 \lambda \mathbf{z} 3 \mathbf{r d}}=$ elimination half-life after the third administration.

\section{INTRODUCTION}

Marbofloxacin is a fluoroquinolone antibacterial compound that has a large spectrum of activity against gram-positive, gram-negative strains and Mycoplasma spp. (Spreng et al., 1995; Thomas et al., 2002). Marbofloxacin is approved for use in companion animals for the treatment of respiratory, urinary, and dermatological diseases in the United States and in Europe; in cattle and pigs for the treatment of respiratory, soft tissue, and gastrointestinal infectious diseases in Europe; and for the treatment of acute Escherichia coli mastitis in the United Kingdom. Its pharmacokinetic profile has been already described in dogs (Schneider et al., 1996), pigs (Petracca et al., 1993), goats (Waxman et al., 2001), horses (Carretero et al., 2002; BousquetMelou et al., 2002), and cattle (Thomas et al., 1994). Shem-Tov et al. (1997) have described in detail the serum and milk pharmacokinetics of marbofloxacin in lactating cows. However, their findings that marbofloxacin was eliminated more gradually from milk than from serum should be taken cautiously. Indeed, in the publication of Kaartinen et al. (1995) describing the pharmacokinetics of enrofloxacin in lactating cows, only ciprofloxacin, the active metabolite of enrofloxacin, accumulated in milk. Enrofloxacin itself was eliminated in milk at the same rate as in serum. The present work 
was carried out to clarify the findings obtained by Shem-Tov et al. (1997) by implementing two kinetic trials with lactating cows. The first trial involved eight lactating cows; plasma and milk profiles of marbofloxacin were determined after repeated intramuscular administrations. The second trial was carried out to assess the possible excretion of marbofloxacin metabolites in milk. It involved four lactating cows, which received a single intramuscular administration of marbofloxacin. $\mathrm{N}$-Desmethyl-marbofloxacin and $\mathrm{N}$-oxide-marbofloxacin, already identified in dog plasma (Lefebvre et al., 1998), were looked for as putative metabolites in the milk. Another aim of the present work was to evaluate the potential of marbofloxacin for the treatment of clinical mastitis. For this purpose, the pharmacodynamic characteristics of marbofloxacin (minimum inhibitory concentration [MIC] and bactericidal activity) against representative susceptible mastitis pathogens were determined.

\section{MATERIALS AND METHODS}

\section{Animals}

Clinically healthy lactating cows from the breeds Prim'Holstein and Montbéliarde were used. They were between 3 and $6 \mathrm{yr}$ old and weighed 483 to $694 \mathrm{~kg}$. The number of the actual lactation cycle of the participating cows were between one and four, and the daily milk production ranged from 11 to $27 \mathrm{~L}$. The cows were kept individually in straw-bedded pens located in a dynamically ventilated room. They were machine-milked twice daily at about 8 a.m. and 6 p.m. Hay was provided ad libitum, about 8 to $10 \mathrm{~kg}$ per animal, together with roughly $2 \mathrm{~kg}$ of concentrate, pellets containing approximately $18 \% \mathrm{CP}$, and about $150 \mathrm{~g}$ of a mineral and vitamin supplement. Water was available ad libitum.

\section{Test Drug and Experimental Design}

First trial. Marbofloxacin was given as a $10 \%$ solution for injection (Marbocyl 10\%, Vétoquinol, Lure, France). The dose rate was $2 \mathrm{mg} / \mathrm{kg}$ once daily, for $3 \mathrm{~d}$, and all animals were treated on the same day. The intramuscular injections were given alternatively into the left and right neck muscles, just after the morning milking. For the assay of the drug, blood samples of 10 $\mathrm{mL}$ were taken by venipuncture of the left or right jugular vein into heparinized Vacutainer tubes. The blood samples were taken at the following times: 0,15 , 30 , and $45 \mathrm{~min} ; 1,1.5,2,3,4,6,8,10,23,28,34,47$, $48.5,49,50,51,52,54,56,58,71,76,82$, and $95 \mathrm{~h}$. The 0 time point corresponded to a sample that was taken just before the first administration of marbofloxacin. The administrations were performed at the follow- ing time points: 0,24 , and $48 \mathrm{~h}$. About $30 \mathrm{~min}$ after sampling, the blood was centrifuged at $3500 \mathrm{rpm}$ and at $5^{\circ} \mathrm{C}$ during $10 \mathrm{~min}$. The obtained plasma was divided into two aliquots of $1 \mathrm{~mL}$ each, which were deep frozen until analysis. Milk samples were obtained by manual pressure of the teats, with the first portion being discarded. A sample was collected at the following time points: $0,30 \mathrm{~min} ; 1,2,3,4,6,10,23,28,34,47,49,50$, $51,52,54,58,71,76,82$, and $95 \mathrm{~h}$. As for plasma, the 0 time point corresponded to a sample that was taken just before the first administration. The samples that were collected at $0,23,47,71$, and $95 \mathrm{~h}$ were part of the morning routine milking, and the samples collected at $10,34,58$, and $82 \mathrm{~h}$ were part of the evening routine milking. For each sample, three aliquots of approximately $2 \mathrm{~mL}$ of milk were deep frozen until analysis.

Second trial. Marbofloxacin (Marbocyl 10\%) was given as a single intramuscular dose of $2 \mathrm{mg} / \mathrm{kg}$ to four cows into the left or right neck muscles, just after the morning milking. For the purpose of the drug and metabolite assay, milk samples were taken at the following times: $0,0.5,1,2,3,4,6,10,24,28,34,48,52,58$, and $72 \mathrm{~h}$ after the administration. The 0 time point corresponded to a sample that was taken just before the administration. The 24-, 48-, and 72-h time points corresponded to the morning routine milking, and 10-, 34-, and 58-h time points corresponded to the evening routine milking. The sampling and preparation of aliquots were performed as described for the first trial.

\section{Drug Assay}

The HPLC assay method of marbofloxacin in bovine plasma was comparable to the method in dog plasma, which has already been described (Schneider et al., 1996). Briefly, to $1 \mathrm{~mL}$ of plasma were added $200 \mu \mathrm{L}$ of internal standard solution (ofloxacin at $5 \mu \mathrm{g} / \mathrm{mL}$ in a pH 7 buffer) and $8 \mathrm{~mL}$ of dichloromethane. The mixture was agitated during $10 \mathrm{~min}$ and thereafter centrifuged at $5000 \mathrm{rpm}$, at $5^{\circ} \mathrm{C}$ during $10 \mathrm{~min}$. The organic layer was separated and evaporated at 35 to $40^{\circ} \mathrm{C}$ under a gentle nitrogen flow. The dry residue was dissolved in $200 \mu \mathrm{L}$ of mobile phase by Vortex mixing and sonication. About $50 \mu \mathrm{L}$ of the dissolved extract was injected into the chromatographic system. This system consisted of a Waters 510 solvent pump, a Waters $717+$ automated refrigerated injector and a Waters 486 UV detector. The mobile phase was a mixture of $\mathrm{pH} 2.7$ buffer $87.5 \%$, methanol $10 \%$, and acetonitrile $2.5 \%$, which was delivered at a flow rate of $1 \mathrm{~mL} / \mathrm{min}$. The separation was performed on a Merck Lichrospher $5 \mu \mathrm{m}$ RP18 encapped analytical column ( $250 \mathrm{~mm}$ in length and $4 \mathrm{~mm}$ in i.d.) fitted with a Merck 5- $\mu \mathrm{m}$ RP18 encapped precolumn (4 $\mathrm{mm}$ in length and $4 \mathrm{~mm}$ in i.d.). The column and the 
precolumn were operated at $30^{\circ} \mathrm{C}$, and the detection wavelength was $295 \mathrm{~nm}$. Under these conditions, the retention time of marbofloxacin and ofloxacin was about 10 and $14 \mathrm{~min}$, respectively. The limit of quantification of the method was $0.01 \mu \mathrm{g} / \mathrm{mL}$, and the linearity range was from 0.01 to $5 \mu \mathrm{g} / \mathrm{mL}$. The reproducibility coefficients of variation were better than $5 \%$, and the recovery was greater than $70 \%$.

The method for the extraction of marbofloxacin in milk samples was very similar to the plasma method. Two changes were introduced; first, to $1 \mathrm{~mL}$ of milk only $50 \mu \mathrm{L}$ of internal standard solution was added (ofloxacin at $1 \mu \mathrm{g} / \mathrm{mL}$ in a $\mathrm{pH} 7$ buffer) and second, the dissolved extract was centrifuged at $3000 \mathrm{rpm}$ and at $5{ }^{\circ} \mathrm{C}$ for 5 min before injection into the HPLC system. The chromatographic conditions were also identical, except for the detection, which was fluorimetric, with an excitation wavelength set to $295 \mathrm{~nm}$ and an emission wavelength set to $500 \mathrm{~nm}$. The limit of quantification was $0.001 \mu \mathrm{g} / \mathrm{mL}$, and the linearity range was 0.001 to $1 \mu \mathrm{g} / \mathrm{mL}$. The reproducibility coefficients of variation were better than $8 \%$, and the recovery was greater than $75 \%$.

For the assay of the metabolites, the method was comparable to the published method for dog plasma (Lefebvre et al., 1998) with some modifications. Five hundred microliters of SDS $0.01 M$ were added to $1 \mathrm{~mL}$ of milk together with $200 \mu \mathrm{L}$ of a $0.5 \mu \mathrm{g} / \mathrm{mL}$ enrofloxacin solution (internal standard). The extraction was performed with $8 \mathrm{~mL}$ of dichloromethane. The separation was performed on a Waters Symmetry C18 analytical column (150 $\mathrm{mm}$ in length and $3.9 \mathrm{~mm}$ in i.d.) fitted with a Waters Symmetry C18 precolumn $(4 \mathrm{~mm}$ in length and $3.9 \mathrm{~mm}$ in i.d.). The column and the precolumn were operated at $35^{\circ} \mathrm{C}$. The limit of quantification of both metabolites was $0.05 \mu \mathrm{g} / \mathrm{mL}$, and their retention time was approximately $8 \mathrm{~min}$ for $\mathrm{N}$-desmethyl-marbofloxacin and 13 min for $\mathrm{N}$-oxide-marbofloxacin. The $\mathrm{N}$-desmethyl-marbofloxacin and the N-oxide-marbofloxacin were obtained from Roche (Basle, Switzerland). Typical chromatograms are shown in Figure 1.

\section{Pharmacokinetic Evaluation}

Both model-dependent and model-independent pharmacokinetic evaluations were performed using the WinNonlin (Pharsight Corporation, Mountain View, CA) software. For the plasma data, the profile obtained after the first administration, was fitted to a compartmental model. The whole plasma data was also submitted to a noncompartmental analysis. Milk data were analyzed using only a noncompartmental method.

An open mono-compartmental model with a first-order absorption described best the plasma profile of mar-
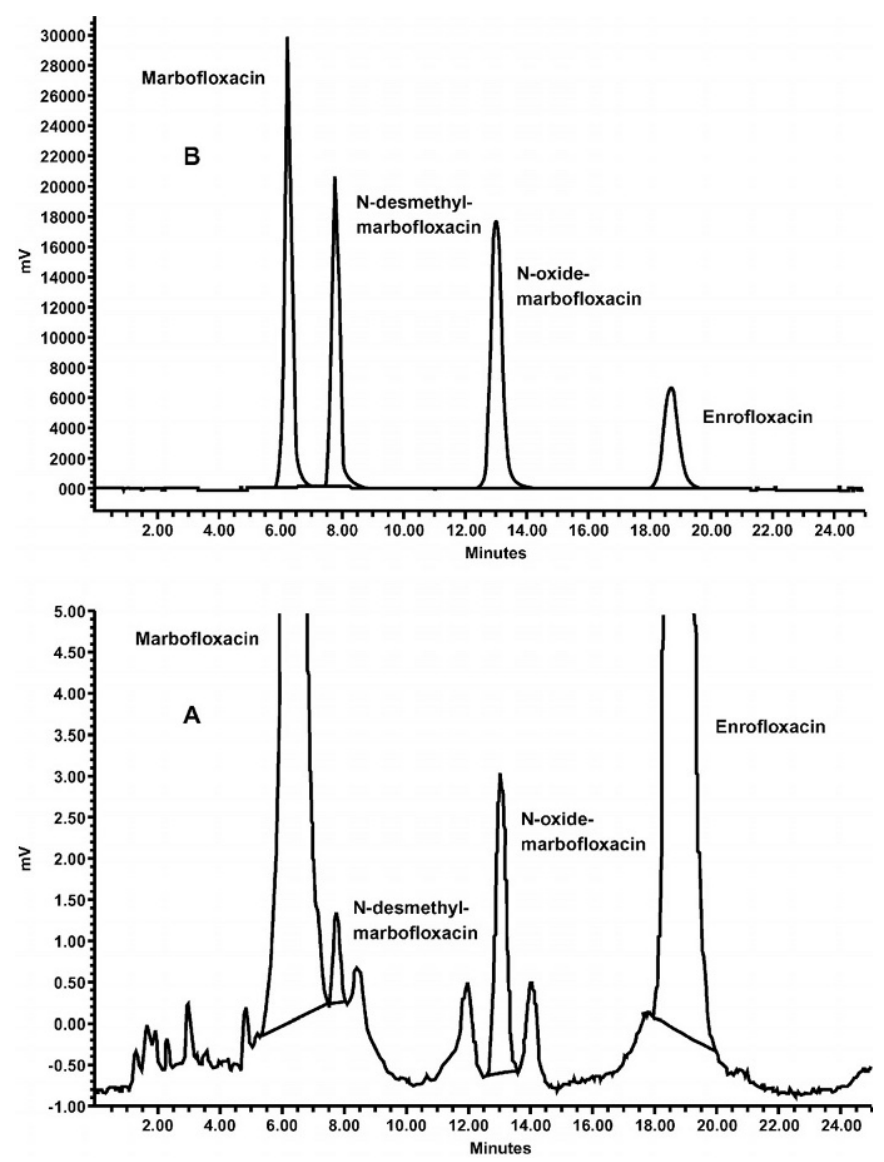

Figure 1. Chromatogram of a standard solution of marbofloxacin. $\mathrm{N}$-desmethyl-marbofloxacin, N-oxide-marbofloxacin, enrofloxacin (B) and of a milk study sample taken $6 \mathrm{~h}$ after an intramuscular marbofloxacin administration at a dose of $2 \mathrm{mg} / \mathrm{kg}$ (A).

bofloxacin after the first administration. The equation of the model was: $\mathrm{C}(\mathrm{t})=-\mathrm{e}^{(\mathrm{K} 01 \mathrm{t})}+\left(\mathrm{DK}_{01} / \mathrm{V}\left(\mathrm{K}_{01}-\mathrm{K}_{10}\right)\right)$ $\mathrm{e}^{(-\mathrm{K} 10 \mathrm{t})}$, with $\mathrm{C}(\mathrm{t})=$ drug concentration at time $\mathrm{t}, \mathrm{D}=$ the dose, $\mathrm{V}=$ the apparent volume of distribution, $\mathrm{K}_{01}=$ the absorption rate constant, and $\mathrm{K}_{10}=$ the elimination rate constant. The pharmacokinetic parameters (rate constants, half-lives, apparent volume of distribution) were calculated from the classical equations associated with the compartmental analysis (Gibaldi and Perrier, 1982). The observed maximum concentration $\left(\mathbf{C}_{\mathbf{m a x}}\right)$, and the occurrence time of the maximum plasma concentration $\left(\mathbf{T}_{\max }\right)$ were directly obtained from the datasets. The area under the concentration-time curve until the last measurable time point $\left(\mathbf{A U C} \mathbf{C}_{\text {last }}\right)$, and the mean residence time (MRT last $_{\text {) }}$ until the last measurable time point in plasma and milk were calculated with a noncompartmental method, using the linear trapezoidal rule. Extrapolation to infinity of the $\mathrm{AUC}_{\text {last }}\left(\mathbf{A U C} \mathbf{C}_{\mathbf{i n f}}\right)$, was obtained by adding the following term to the $\mathrm{AUC}_{\text {last }}: \mathrm{C}_{\text {last }} / \lambda \mathrm{z}$, where $\mathrm{C}_{\text {last }}$ is the last measurable con- 
centration and $\lambda \mathrm{z}$ is the slope of the regression line obtained with the last observed concentrations.

\section{Pharmacodynamics Evaluation}

Bacteria. All bacterial isolates were from milk samples collected from cows suspected of having IMI. The samples were taken before starting a treatment, and they were collected between January 1, 1999, and December 31, 1999, from several European countries. The samples were shipped to different laboratories located near the sampling sites to reduce the time in transport. Primary cultures of milk samples were performed by plating $100 \mu \mathrm{L}$ of milk on MacConkey agar (Difco) for Escherichia coli strain isolation and on Colombia agar (Difco) with 5\% of defibrinated sheep blood for Staphylococcus aureus strain isolation. The plates were incubated at 35 to $37^{\circ} \mathrm{C}$ for 24 to $48 \mathrm{~h}$. Escherichia coli and $S$. aureus were chosen as being the target pathogens of marbofloxacin. Other strains involved in mastitis, such as Streptococci, are less susceptible to fluoroquinolones in general. Escherichia coli was identified by colony morphology, Gram-staining characteristics, oxidase, and biochemical reactions on MacConkey agar and API 20E (BioMerieux S.A. Marcy-l'Etoile, France). Staphylococcus aureus was identified by colony morphology, hemolytic patterns on Columbia agar with 5\% of defibrinated sheep blood, Gram-staining characteristics, catalase, positive Slidex Staph test, and ID 32 Staph (BioMerieux S.A.). A total of 68 E. coli (3 from Belgium, 37 from France, 6 from UK, 10 from the Netherlands, and 12 from Germany) and 56 S. aureus (2 from Belgium, 30 from France, 4 from England, 10 from the Netherlands, and 10 from Germany) strains were isolated. Isolates were then shipped to the microbiology laboratory of the Research and Development Department of Vétoquinol S.A. (Lure, France) for MIC determinations. Upon receipt, all isolates were streaked on Trypticase soy agar (Bio-Rad), incubated for $24 \mathrm{~h}$ at 35 $\pm 2^{\circ} \mathrm{C}$, and tested for purity. The isolates were then stored at $-70^{\circ} \mathrm{C}$ in Trypticase soy broth containing $10 \%$ glycerol until further testing.

MIC determination. Before the MIC determination, all isolates were regrown by three subcultures on trypticase soy agar (Difco) for $E$. coli strains and Columbia agar (Difco) with $5 \%$ of defibrinated sheep blood for $S$. aureus strains and incubated for 18 to $24 \mathrm{~h}$ at $35 \pm 2^{\circ} \mathrm{C}$. The MIC determination of marbofloxacin was performed by the broth microdilution method according to the National Committee for Clinical Laboratory Standards (NCCLS, Wayne, PA) guideline (M31-A) for testing veterinary pathogens (NCCLS Document M31-A, 1999). The MIC were determined in 96 -well microtiter plates, and the dilutions tested were 0.002 to 2 and
0.008 to $8 \mu \mathrm{g} / \mathrm{mL}$. Quality control strains were included in each batch of organisms tested: $S$. aureus ATCC 29213 (American Type Culture Collection) or E. coli ATCC 25922. The MIC were determined after 18 to 24 $\mathrm{h}$ of incubation at $35 \pm 2^{\circ} \mathrm{C}$ under aerobic conditions. The first dilution with no visible growth was considered as the MIC for each strain. The concentration of antibiotic able to inhibit the visible growth of $50 \%$ of a population of microorganisms $\left(\mathbf{M I C}_{\mathbf{5 0}}\right)$ and the concentration of antibiotic able to inhibit the visible growth of $90 \%$ of a population of microorganisms ( $\mathbf{M I C}_{\mathbf{9 0}}$ ) were calculated for both species as well as the minimum and maximum MIC (range).

The marbofloxacin breakpoints (validated following the NCCLS guideline [NCCLS Document M37-A, 1999]) for pathogenic bacteria isolated from pets and large animals are the following:

For susceptible strains MIC $\leq 1 \mu \mathrm{g} / \mathrm{mL}$ and a zone inhibition diameter $\geq 18 \mathrm{~mm}$, for intermediate strains $\mathrm{MIC}=2 \mu \mathrm{g} / \mathrm{mL}$ and a zone inhibition diameter [15-17] $\mathrm{mm}$, for resistant strains a MIC $\geq 4 \mu \mathrm{g} / \mathrm{mL}$ and a zone inhibition diameter $\leq 14 \mathrm{~mm}$.

Determination of bactericidal activity of marbofloxacin. Determination of the bactericidal activity of marbofloxacin was carried out on two strains of $S$. aureus isolated in France in 2001 from mastitis, which had respectively a MIC of 0.12 and $0.5 \mu \mathrm{g} / \mathrm{mL}$. These MIC values were just below the $\mathrm{MIC}_{50}$ and just above the $\mathrm{MIC}_{90}$ obtained in the present field study (see Table 1). The used methodology adheres to the NCCLS guideline M26-A (1999).

Before the determination of bactericidal activity, the two isolates were revived by subcultures on Columbia agar (Difco) with 5\% of defibrinated sheep blood and incubated for 18 to $24 \mathrm{~h}$ at $35 \pm 2^{\circ} \mathrm{C}$. Five well-isolated colonies were collected, put in $10 \mathrm{~mL}$ of Mueller-Hinton broth (Difco), and incubated for $6 \mathrm{~h}$ at $37 \pm 2^{\circ} \mathrm{C}$. The inoculum size was adjusted to about $10^{6} \mathrm{cfu} / \mathrm{mL}$ by dilution in Mueller-Hinton broth.

The time-kill curve method was performed in glass tubes containing $1.8 \mathrm{~mL}$ of bacterial suspension in Mueller-Hinton (Difco) broth and $0.2 \mathrm{~mL}$ of a marbofloxacin solution in Mueller-Hinton broth to obtain a final concentration in tube of $0-, 1-, 2-, 4-$, and 8fold the marbofloxacin MIC of each tested bacterium. These tubes were incubated in a water bath at $35 \pm 2^{\circ} \mathrm{C}$ under agitation. To determine the bacterial count, a sample of $50 \mu \mathrm{L}$ was taken at $0,1,2,4,6$, and $24 \mathrm{~h}$ of incubation and put into sterile 96-well microtiter plates. Thereafter, six successive dilutions with $150 \mu \mathrm{L}$ of sterile saline solution $(0.9 \%$ of $\mathrm{NaCl})$ containing $0.02 \%$ of Tween 80 were performed. For each dilution, a sample of $50 \mu \mathrm{L}$ was taken. An inoculation of $25 \mu \mathrm{L}$ (spot) of each dilution was carried out on trypticase soy 
Table 1. Marbofloxacin minimum inhibitory concentratrion (MIC) determination and susceptibility evaluation on Staphylococcus aureus and Escherichia coli strains isolated in 1999.

\begin{tabular}{llllllll}
\hline Strain & $\mathrm{n}^{1}$ & Range $^{2}$ & $\mathrm{MIC}_{50}{ }^{2}$ & $\mathrm{MIC}_{90}{ }^{2}$ & $(\%)^{3} \mathrm{~S}^{4}$ & $(\%) \mathrm{I}^{5}$ & $(\%) \mathrm{R}^{6}$ \\
\hline Escherichia coli & 68 & $0.008-4$ & 0.011 & 0.016 & 98.6 & 0 & 1.4 \\
Staphylococcus aureus & 56 & $0.06-0.5$ & 0.154 & 0.229 & 100 & 0 & 0 \\
\hline
\end{tabular}

${ }^{1} \mathrm{n}$ : number of strains.

${ }^{2}$ Range, $\mathrm{MIC}_{50}$ and $\mathrm{MIC}_{90}$ were in $\mu \mathrm{g} / \mathrm{ml}$.

$3 \%$ : Percentage of total collected strains.

${ }^{4} \mathrm{~S}$ : sensitive.

${ }^{5} \mathrm{I}$ : intermediate.

${ }^{6} \mathrm{R}$ : resistant.

agar (Difco) with $1 \%$ active charcoal and $1 \% \mathrm{MgSO}_{4}$ $7 \mathrm{H}_{2} \mathrm{O}$ to avoid marbofloxacin carryover. The limit of detection was $160 \mathrm{cfu} / \mathrm{mL}$. Each plate, prepared in duplicate, was incubated 18 to $24 \mathrm{~h}$ at $35 \pm 2^{\circ} \mathrm{C}$ before count. A bactericidal activity of an antibiotic corresponds to a reduction equal to or more than $3 \log _{10} \mathrm{cfu} /$ $\mathrm{mL}$ of the inoculum size after $24 \mathrm{~h}$ of incubation. If this reduction appears in less than $6 \mathrm{~h}$, the activity of the antibiotic is considered as concentration dependent and if the reduction appears only after $6 \mathrm{~h}$, the activity is considered as time dependent.

The fluoroquinolones used in veterinary medicine are considered to have a concentration-dependent bactericidal activity on gram-negative aerobic bacteria and a time-dependent bactericidal activity on gram-positive aerobic bacteria.

\section{Pharmacokinetic/Pharmacodynamic Integration}

To predict a possible efficacy of antibiotics against different target pathogens, it is commonly accepted that the AUC/MIC ratio and $\mathrm{C}_{\max } / \mathrm{MIC}$ ratio are suitable parameters, especially for fluoroquinolones (Hyatt et al., 1995; Schentag, 1999; Pickerill et al., 2000). For the calculation of the former ratio in milk, the AUC after the last dose until the end of a dosage interval was used, i.e., $\mathrm{AUC}_{48-71}$. The second term in the ratio was the $\mathrm{MIC}_{90}$ against both target pathogens, E. coli and $S$. aureus. This parameter is associated with a whole population of strains and not only with a single MIC value, making it much more predictive. The $\mathrm{C}_{\max } / \mathrm{MIC}$ ratio was calculated with the peak milk concentration obtained after the third dose, the pharmacodynamic parameter was the same as in the first ratio.

\section{RESULTS}

\section{Plasma Kinetics}

The mean plasma concentration-time profile of marbofloxacin is shown in Figure 2. The absorption of marbofloxacin into the systemic circulation was very fast, with a mean absorption half-life $\left(\mathbf{T}_{1 / 2 \mathbf{K} 01}\right)$ of about 10 min and a $\mathrm{T}_{\max }$ of approximately $45 \mathrm{~min}$ (Table 2). Both parameters were determined after the first administration. The $\mathrm{C}_{\max }$ observed after the first administration $\left(\mathbf{C}_{\max } \mathbf{1}^{\text {st }}\right.$ obs) was $1.667 \mu \mathrm{g} / \mathrm{ml}$. The calculated $\mathrm{T}_{\max }$ and $\mathrm{C}_{\max }$ obtained by means of compartmental modeling were very close to the observed ones, indicating that the fitting parameters were adequate. The elimination $\left(\mathbf{T}_{1 / 2 \mathrm{~K} 10}\right)$, as determined by compartmental modeling, was relatively fast at $2.53 \mathrm{~h}$. After the third administration, two elimination phases could be observed; the second slower phase had a half-life $\left(\mathbf{T}_{1 / 2 \lambda \text { zrd }}\right)$ of $6.27 \mathrm{~h}$, which was determined by the noncompartmental analysis. The area under the curve during the first dosing inter-

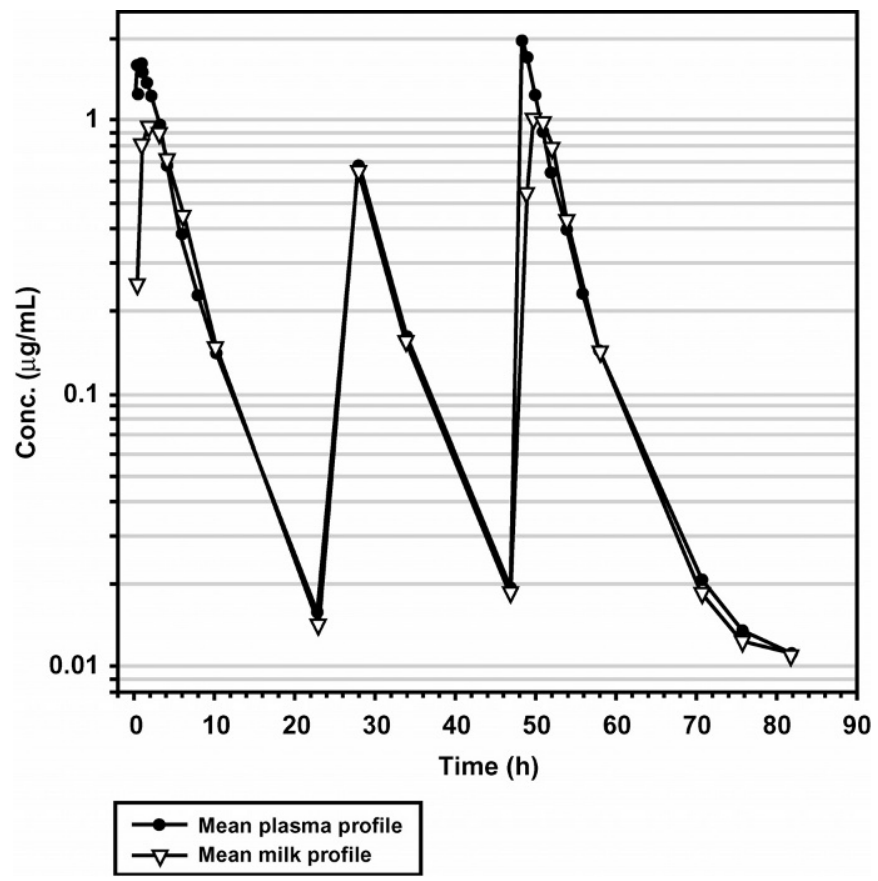

Figure 2. Mean plasma and milk concentration-time profile of marbofloxacin in the dairy cow after repeated intramuscular administrations at a dose rate of $2 \mathrm{mg} / \mathrm{kg} \mathrm{q} 24 \mathrm{~h}$ for $3 \mathrm{~d}$. 
Table 2. Comparison of the pharmacokinetic parameters in milk and plasma.

\begin{tabular}{|c|c|c|c|c|}
\hline \multirow[b]{2}{*}{ Parameters } & \multicolumn{2}{|c|}{ Plasma } & \multicolumn{2}{|c|}{ Milk } \\
\hline & Mean & $\mathrm{SD}$ & Mean & $\mathrm{SD}$ \\
\hline Volume $^{1} / \mathrm{F}^{2}(\mu \mathrm{g} / \mathrm{ml})$ & 1.032 & 0.1134 & & \\
\hline $\mathrm{K}_{\mathrm{a}}^{3}\left(\mathrm{~h}^{-1}\right)$ & 4.754 & 2.034 & & \\
\hline $\mathrm{K}_{10}^{4}\left(\mathrm{~h}^{-1}\right)$ & 0.2771 & 0.03525 & & \\
\hline $\mathrm{T}_{1 / 2 \mathrm{~K} 01}^{5}(\mathrm{~h})$ & 0.17 & 0.06 & & \\
\hline $\mathrm{T}_{1 / 2 \mathrm{~K} 10}{ }^{6}(\mathrm{~h})$ & 2.53 & 0.28 & & \\
\hline $\mathrm{T}_{\max } \mathrm{cal}^{7}(\mathrm{~h})$ & 0.69 & 0.17 & & \\
\hline $\mathrm{T}_{\max } \mathrm{Obs}^{8}(\mathrm{~h})$ & 0.72 & 0.16 & 2.50 & 0.93 \\
\hline $\mathrm{C}_{\max } 1^{\text {st }} \mathrm{cal}^{9}(\mu \mathrm{g} / \mathrm{ml})$ & 1.618 & 0.2140 & & \\
\hline $\mathrm{C}_{\max } 1^{\text {st }} \operatorname{obs}^{10}(\mu \mathrm{g} / \mathrm{ml})$ & 1.667 & 0.1956 & 1.024 & 0.2563 \\
\hline $\mathrm{C}_{\max } 3^{\text {rd }} \operatorname{obs}^{11}(\mu \mathrm{g} / \mathrm{ml})$ & 1.978 & 0.2392 & 1.074 & 0.2317 \\
\hline $\mathrm{AUC}^{12}(\mu \mathrm{g} \cdot \mathrm{h} / \mathrm{ml})$ & 7.146 & 1.090 & & \\
\hline $\mathrm{C} 23^{13}(\mu \mathrm{g} / \mathrm{ml})$ & 0.01708 & 0.004120 & 0.01257 & 0.003998 \\
\hline $\mathrm{C} 71^{14}(\mu \mathrm{g} / \mathrm{ml})$ & 0.02082 & 0.004814 & 0.01603 & 0.005894 \\
\hline $\mathrm{T}_{1 / 2 \lambda z 1 s t}(\mathrm{~h})$ & & & 3.11 & 0.42 \\
\hline $\mathrm{T}_{1 / 2 \lambda z 3 \mathrm{rd}}(\mathrm{h})$ & 6.27 & 2.80 & 9.94 & 1.18 \\
\hline $\mathrm{AUC}_{0-23} 17(\mu \mathrm{g} \cdot \mathrm{h} / \mathrm{ml})$ & 7.648 & 1.184 & 6.383 & 1.059 \\
\hline $\mathrm{AUC}_{48-71}{ }^{18}(\mu \mathrm{g} \cdot \mathrm{h} / \mathrm{ml})$ & 8.165 & 1.362 & 6.513 & 1.256 \\
\hline
\end{tabular}

${ }^{1}$ Volume of distribution.

${ }^{2}$ Absolute bioavailability.

${ }^{3}$ Apparent absorption rate constant.

${ }^{4}$ Elimination rate constant.

${ }^{5}$ Absorption half-life.

${ }^{6}$ Elimination half-life.

${ }^{7}$ Calculated occurrence time of the maximum plasma concentration. ${ }^{8}$ Observed occurrence time of the maximum plasma concentration.

${ }^{9}$ Maximum concentration calculated after the first administration.

${ }^{10}$ Maximum concentration observed after the first administration.

${ }^{11}$ Maximum concentration observed after the third administration.

${ }^{12}$ Area under the curve.

${ }^{13}$ Concentration observed $23 \mathrm{~h}$ after the first administration.

${ }^{14}$ Concentration observed $23 \mathrm{~h}$ after the third administration.

${ }^{15}$ Elimination half-life after the first administration.

${ }^{16}$ Elimination half-life after the third administration.

${ }^{17}$ Partial area under the curve obtained after the first administration.

${ }^{18} \mathrm{Partial}$ area under the curve calculated from the third administration till 23 hours later.

val $\left(\mathbf{A U C}_{\mathbf{0 - 2 3}}\right)$, as determined with linear trapezoidal method, was $7.648 \mu \mathrm{g} \mathrm{h} / \mathrm{mL}$.

After the third administration, some parameters were slightly increased (Table 2). They were compared to the parameters obtained after the first administration by one-sided $t$ tests. The mean $\mathrm{C}_{\max }$ observed after the third administration $\left(\mathbf{C}_{\text {max }} 3^{\text {rd }} \mathbf{o b s}\right)$ was $1.978 \mu \mathrm{g} /$ $\mathrm{mL}$ and was increased by about $20 \%$, this difference being statistically significant $(P=0.023)$. The mean concentration observed $23 \mathrm{~h}$ after the third administration (C71), $0.02082 \mu \mathrm{g} / \mathrm{mL}$, was also increased by about $20 \%$ when compared with the mean concentration observed $23 \mathrm{~h}$ after the first administration (C23), 0.01708 $\mu \mathrm{g} / \mathrm{mL}$, this difference also being statistically significant $(P=0.022)$. The mean partial AUC calculated from the third administration until $23 \mathrm{~h}$ later $\left(\mathrm{AUC}_{48-71}\right)$ was increased only by roughly $10 \%$ when compared to the partial AUC obtained after the first administration. The difference between both partial areas was also statistically significant $(P=0.007)$.

\section{Milk Kinetics}

As shown in Figure 2, the concentration-time profile of marbofloxacin in milk closely paralleled the plasma profile. The occurrence of marbofloxacin in milk was somewhat delayed compared with the systemic absorption. Indeed, the mean observed $\mathrm{T}_{\max }$ after the first administration was $2.50 \mathrm{~h}$. The mean $\mathrm{C}_{\max } 1^{\text {st }}$ obs was $1.024 \mu \mathrm{g} / \mathrm{mL}$. This concentration was slightly increased after the third administration (about 10\%), with a mean $\mathrm{C}_{\max } 3^{\text {rd }}$ obs value of $1.074 \mu \mathrm{g} / \mathrm{mL}$, although this increase was not statistically significant $(P=0.37)$. The mean concentration observed $23 \mathrm{~h}$ after the third administration (C71), $0.01603 \mu \mathrm{g} / \mathrm{mL}$, was increased by about $30 \%$ when compared with the mean concentration observed $23 \mathrm{~h}$ after the first administration (C23), $0.01257 \mu \mathrm{g} /$ $\mathrm{mL}$, this difference being statistically significant $(P=$ 0.028). The mean partial AUC calculated from the third administration until $23 \mathrm{~h}$ later $\left(\mathrm{AUC}_{48-71}=6.513 \mu \mathrm{g}\right.$ $\mathrm{h} / \mathrm{mL}$ ) was only marginally increased by around $2 \%$ compared with the partial AUC obtained after the first administration $\left(\mathrm{AUC}_{0-23}=6.383 \mu \mathrm{g} \mathrm{h} / \mathrm{mL}\right)$. The difference between both partial areas was not statistically significant $(P=0.63)$. It can be concluded that there is no accumulation in milk.

The elimination half-life after the first administration, $\left(\mathbf{T}_{1 / 2 \lambda \mathbf{z} 1 \mathrm{st}}\right)$, was relatively fast, with a mean value of $3.11 \mathrm{~h}$. The elimination half-life after the third administration, $\left(\mathbf{T}_{1 / 2 \lambda \mathbf{z} 3 \mathbf{r d}}\right)$, was much longer, with a mean value of $9.94 \mathrm{~h}$. This difference can be explained by the time points that are available for the calculation of the half-lives. After the first administration, samples were available until $23 \mathrm{~h}$ later, whereas after the third administration, samples were available until $47 \mathrm{~h}$ later. Therefore, $\mathrm{T}_{1 / 2 \lambda z 3 r d}$ was calculated using later time points belonging to a second slower elimination phase. This second slower elimination phase occurred also in the plasma.

Both metabolites were detected in the milk, but their concentrations were below the limit of quantification for all time points. Thus, they did not contribute significantly to the elimination of marbofloxacin.

\section{Pharmacodynamics}

The obtained MIC range, $\mathrm{MIC}_{50}$, and $\mathrm{MIC}_{90}$ values are given in Table 1. Escherichia coli strains were very sensitive to marbofloxacin with a very low $\mathrm{MIC}_{90}(0.016$ $\mu \mathrm{g} / \mathrm{mL}$ ) and a relatively narrow MIC range. Only one 
strain was resistant to marbofloxacin. The marbofloxacin MIC range was close to published values for enrofloxacin (Von Walser et al., 1993), with a MIC range of 0.03 to $1.0 \mu \mathrm{g} / \mathrm{mL}$. Nevertheless, the $\mathrm{MIC}_{50}$ and $\mathrm{MIC}_{90}$ values were better for marbofloxacin than for enrofloxacin, which has the following values: $\mathrm{MIC}_{50}$ of $0.04 \mu \mathrm{g} /$ $\mathrm{mL}$ and $\mathrm{MIC}_{90}$ of $0.14 \mu \mathrm{g} / \mathrm{mL}$. The marbofloxacin activity was also better than the activity of norfloxacin (Schlegelva et al., 2002) against $E$. coli isolated from bovine mastitis with a MIC range of 0.25 to $0.5 \mu \mathrm{g} / \mathrm{mL}$, a $\mathrm{MIC}_{50}$ of $0.25 \mu \mathrm{g} / \mathrm{mL}$ and a $\mathrm{MIC}_{90}$ of $0.5 \mu \mathrm{g} / \mathrm{mL}$.

Against $S$. aureus, the marbofloxacin $\mathrm{MIC}_{90}$ was higher $(0.229 \mu \mathrm{g} / \mathrm{mL})$ compared with the value against $E$. coli. However, no $S$. aureus strain was resistant to marbofloxacin. In general, the fluoroquinolones, until the third generation, are less active against gram-positive bacteria than against gram-negative bacteria.

These marbofloxacin results against $S$. aureus were comparable to those of danofloxacin ( $\mathrm{MIC}_{90}$ of $0.18 \mu \mathrm{g} /$ $\mathrm{mL}$ ), obtained for $S$. aureus isolated from bovine mastitis (Cruz et al., 1998). In Europe, the enrofloxacin $\mathrm{MIC}_{50}$ and $\mathrm{MIC}_{90}$ values determined against $S$. aureus isolated from bovine mastitis were $=0.06$ to $0.125 \mu \mathrm{g} / \mathrm{mL}$ and $=$ 0.06 to $0.31 \mu \mathrm{g} / \mathrm{mL}$, respectively, with a range of $<0.03$ to $64 \mu \mathrm{g} / \mathrm{mL}$ (Von Walser et al., 1993; Salmon et al., 1998; De Oliveiral et al., 2000). In the United States, the enrofloxacin $\mathrm{MIC}_{50}$ and $\mathrm{MIC}_{90}$ values determined against $S$. aureus isolated from mastitis were higher than in Europe: $=0.25$ to $0.5 \mu \mathrm{g} / \mathrm{mL}$ and $=0.25$ to 0.5 $\mu \mathrm{g} / \mathrm{mL}$, respectively, with a range of $=0.13$ to $1 \mu \mathrm{g} / \mathrm{mL}$ (Watts et al., 1995; Gianneechini et al., 2002). Thus, the results obtained with marbofloxacin were comparable to the results obtained with enrofloxacin. In the two DANMAP reports $(2000,2001)$, the ciprofloxacin MIC values obtained against $S$. aureus isolated from bovine mastitis were similar to the results obtained for marbofloxacin: in 2000 the MIC range was between 0.125 and $2 \mu \mathrm{g} / \mathrm{mL}$, with a $\mathrm{MIC}_{50}$ of $0.25 \mu \mathrm{g} / \mathrm{mL}$ and a $\mathrm{MIC}_{90}$ of $0.5 \mu \mathrm{g} / \mathrm{mL}$; in 2001, the MIC range was between 0.12 and $0.5 \mu \mathrm{g} / \mathrm{mL}$ (the range being lower than in 2000).

The marbofloxacin activity was better than the activity of norfloxacin against $S$. aureus with a MIC range of 1 to $16 \mu \mathrm{g} / \mathrm{mL}$, a $\mathrm{MIC}_{50}$ of $2 \mu \mathrm{g} / \mathrm{mL}$ and a $\mathrm{MIC}_{90}$ of 2 $\mu \mathrm{g} / \mathrm{mL}$ (Schlegelva et al., 2002).

The time-killing curves of both $S$. aureus strains tested were very similar (Figure 3 ). As the susceptibility to marbofloxacin of the two strains tested were representative of $50 \%$ of the population and $90 \%$ of the population, we could consider that the time-killing curve indicates that marbofloxacin has a time-dependent bactericidal activity at a minimum of fourfold the MIC against all the $S$. aureus strains isolated from bovine mastitis. Thus, the marbofloxacin minimal bactericidal concentration (MBC) of each tested strain was, respec-
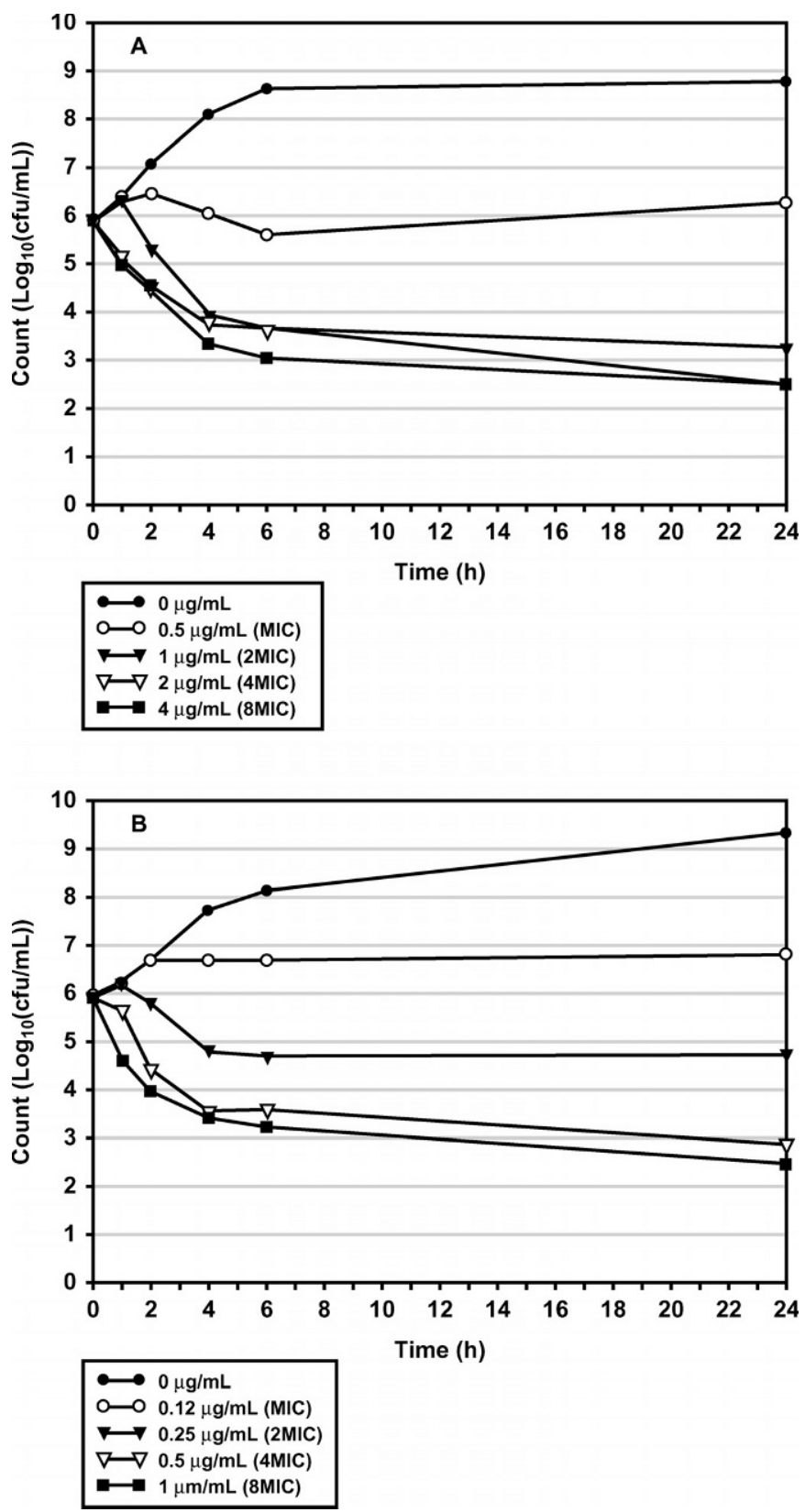

Figure 3. Evolution of the bacterial count in $\log _{10}(\mathrm{cfu} / \mathrm{ml})$ of Staphylococcus aureus (A: minimum inhibitory concentration of 0.5 $\mu \mathrm{g} / \mathrm{mL}$, B: minimum inhibitory concentration of $0.12 \mu \mathrm{g} / \mathrm{mL}$ ) versus time after exposure to different marbofloxacin concentrations.

tively, 0.5 and $2 \mu \mathrm{g} / \mathrm{mL}$. These MBC were similar to the MBC for danofloxacin (Cruz et al., 1998) for the same type of isolates.

At the MIC of the tested strain, the marbofloxacin activity is bacteriostatic for both strains. The marbofloxacin activity at twofold the MIC induced a reduction between 1 to $2 \log _{10} \mathrm{cfu} / \mathrm{mL}$ after $4 \mathrm{~h}$ of incubation without regrowth until $24 \mathrm{~h}$. For the strain with the 
marbofloxacin MIC of $0.5 \mu \mathrm{g} / \mathrm{mL}$, a decrease close to 1 $\log _{10} \mathrm{cfu} / \mathrm{mL}$ at $24 \mathrm{~h}$ can be observed. The marbofloxacin activity at fourfold the MIC or greater, induced a reduction of more than $3 \log _{10} \mathrm{cfu} / \mathrm{mL}$ at $4 \mathrm{~h}$, and a decrease of $1 \log _{10} \mathrm{cfu} / \mathrm{mL}$ at $24 \mathrm{~h}$.

\section{Pharmacokinetic/Pharmacodynamic Integration}

The $\mathrm{C}_{\max } / \mathrm{MIC}$ ratio was 67 for $E$. coli strains and 4.7 for $S$. aureus strains. The AUC/MIC ratio for $E$. coli strains was $407 \mathrm{~h}$ and for $S$. aureus strains, it was $28 \mathrm{~h}$. To be a good predictive tool of clinical cure and avoidance of resistance, the endpoints of these ratios should be at least of 10 for $\mathrm{C}_{\max } / \mathrm{MIC}$ and of $125 \mathrm{~h}$ for AUC/MIC (Hyatt et al., 1995; Schentag, 1999; Pickerill et al., 2000; Schentag et al., 2001). An AUC/MIC ratio of $250 \mathrm{~h}$ indicates that even bacterial eradication may be achieved. Thus, these endpoints are only reached for $E$. coli strains, whereas relatively far away for $S$. aureus strains. However, as the activity of fluoroquinolones against gram-positive strains is rather time dependent, some activity against $S$. aureus strains may be expected.

\section{DISCUSSION}

The first important finding was that the kinetic profile of marbofloxacin in milk paralleled its plasma profile. However, there is a shift of about $2 \mathrm{~h}$ between both $\mathrm{T}_{\max }$ values, resulting in the penetration of marbofloxacin into the milk being delayed. Both profiles are characterized by a two-phase elimination, a first fast phase, $\left(\mathrm{T}_{1 / 2 \mathrm{~K} 10}=2.53 \mathrm{~h}\right.$ in plasma and $\mathrm{T}_{1 / 2 \lambda z 1 \mathrm{st}}=3.11 \mathrm{~h}$ in milk $)$ followed by a second slower phase $\left(\mathrm{T}_{1 / 2 \lambda z 3 \mathrm{rd}}=6.27 \mathrm{~h}\right.$ in plasma and $9.94 \mathrm{~h}$ in milk). The difference between the plasma and milk elimination half-lives of the second phase can be explained by the fact that the limit of quantification (LOQ) of the assay method in milk ( $\mathrm{LOQ}=0.001 \mu \mathrm{g} / \mathrm{mL}$ ) is lower than the $\mathrm{LOQ}$ in plasma ( $\mathrm{LOQ}=0.010 \mu \mathrm{g} / \mathrm{mL})$. Therefore, more concentrationtime points are available in milk for the estimation of the last elimination half-life. The $\mathrm{C}_{\max }$ values were reduced in milk by about 40 to $50 \%$. The concentrations observed $23 \mathrm{~h}$ after the first and the third administration, as well as the partial AUC, were about $20 \%$ lower in milk than in plasma. However, the reduction of the dose-dependent parameters in milk compared with plasma should not affect the ability of marbofloxacin to treat clinical mastitis. Indeed, the pharmacokinetic/ pharmacodynamic integration showed that the elimination characteristics of marbofloxacin in the milk should be appropriate to treat an $E$. coli-induced mastitis following a systemic dose of $2 \mathrm{mg} / \mathrm{kg}$. The obtained $\mathrm{C}_{\max } / \mathrm{MIC}$ ratio was about seven times higher than the recommended ratio, the obtained AUC/MIC ratio being about three times higher than the recommended cure ratio, and it was even higher than the eradication ratio of $250 \mathrm{~h}$. Moreover, the milk concentrations of marbofloxacin stayed above the $\mathrm{MIC}_{90}$ against $E$. coli during the whole dosing interval. Regarding $S$. aureus strains, the cure and eradication predictive ratios are not reached. However, a marbofloxacin concentration of 0.5 $\mu \mathrm{g} / \mathrm{mL}$ was maintained for 5 to $6 \mathrm{~h}$ in the milk. Thus, against the strain with a MIC of $0.5 \mu \mathrm{g} / \mathrm{ml}$ and which is representative of more than $90 \%$ of the population, the activity of marbofloxacin should be at least bacteriostatic for about $6 \mathrm{~h}$. Moreover, against the $S$. aureus strain with a MIC of $0.12 \mu \mathrm{g} / \mathrm{mL}$, representative of more than $50 \%$ of the population, the concentration was maintained above 4 times the MIC for about $6 \mathrm{~h}$. Thus, against these strains, although the PK-PD endpoints are not met, a 100 -fold reduction of the bacterial count may be expected.

This discussion on possible efficacy relies on activity measurements performed in broth mediums. Now, the target medium for mastitis treatment is milk, which is well documented in having some interactions with fluoroquinolones. Some divalent and trivalent metal ions are known to bind to the 3,4- $\beta$-diketone residue of the fluoroquinolones, which is also the binding site to the topoisomerase II. However, between the metal ions, the calcium divalent cation, which occurs in high concentrations in milk, has the lowest association constant, whereas iron and aluminum cations have the highest constants (Ross and Riley, 1994). Furthermore, the paper of Fang and Pyörälä (1996) showed that milk reduced the activity of enrofloxacin against $E$. coli strains only by a factor of 2 . Transposing this twofold activity decrease to marbofloxacin would still result in PK/PD endpoints, which meet the target values against $E$. coli. Against $S$. aureus, the reduction in activity induced by the milk would result in very poor predictive outcome markers at the dose of $2 \mathrm{mg} / \mathrm{kg}$. But, S. aureus is not the target pathogen of the fluoroquinolones for the treatment of clinical mastitis; the combination with a $\beta$-lactamine could easily overcome this potential problem.

Compared with the paper by Shem-Tov et al. (1997), the plasma profile was in good agreement, whereas the milk profile was very different. The dose-dependent parameters, $\mathrm{C}_{\max }$ and AUC, obtained in the milk by ShemTov et al. (1997) were about 2 times lower than in the present study. These lower values of the dose-dependent parameters may be related to the analytical method. Indeed, the authors used a microbiological method for the quantification of marbofloxacin in the serum and milk samples. It seems that their calibration points were prepared in standard solutions and not in 
blank milk. A poorer diffusion of marbofloxacin in the milk when compared with that in the calibration standard samples, thus, may have induced a bias in the measured concentrations of the milk samples. The parallel elimination pattern in plasma and milk was another finding that is inconsistent with the paper of Shem-Tov et al. (1997), which showed a slower elimination in milk, attributed to concomitant excretion of putative active metabolites. We showed in the second trial that the excretion of marbofloxacin metabolites is very limited, and, thus, their contribution to the slower elimination phase is doubtful.

When compared to the relatively shallow kinetic profile of enrofloxacin in milk after intramuscular administration (Kaartinen et al., 1995), the profile of marbofloxacin is rather steep. The authors (Kaartinen et al., 1995) attributed this shallow profile of enrofloxacin to a flip-flop phenomenon resulting from a delayed absorption, which in turn resulted from a pronounced local tissue irritation. This was obviously not the case with marbofloxacin. Another difference between both compounds was the accumulation in milk of the active metabolite of enrofloxacin, ciprofloxacin, which contributes to the overall antibacterial activity. However, this ciprofloxacin milk accumulation can also contribute to the building up of detectable amounts of residue. As marbofloxacin metabolites were not observed in quantifiable amounts, such an accumulation is not expected. The shallow elimination profile in milk is also obtained after intramuscular administration of danofloxacin in dairy cows (Shem-Tov et al., 1998). However, the danofloxacin milk concentrations were also determined by a microbiological method, thus rendering a direct comparison with marbofloxacin rather difficult.

\section{CONCLUSION}

The use of parenteral antimicrobial treatment against coliform mastitis remains controversial. However, Hoeben et al. (2000) and Rantala et al. (2002) showed some benefits in cows with experimentally induced $E$. coli mastitis after administration of parenteral enrofloxacin, especially the reduced milk production decline. Regarding the milk kinetics of marbofloxacin, after repeated intramuscular administrations at a daily dose rate of $2 \mathrm{mg} / \mathrm{kg}$, a possible efficacy against $E$. coliinduced mastitis is expected. Indeed, a field trial (Grandemange and Davot, 2002) using parenteral marbofloxacin in combination with a local cloxacillin treatment showed its efficacy in dairy cows with acute clinical coliform mastitis. Some efficacy against $S$. aureusinduced infections is also expected, especially if the parenteral marbofloxacin treatment is associated with a local $\beta$-lactamine treatment, as was the case in the trial of Grandemange and Davot (2002). However, larger field trials should be performed to confirm these results. Furthermore, the steep marbofloxacin milk profile, which is parallel to the plasma profile, also showed that there is no local irritation at the injection site and, hence, that the milk profile should be reproducible from one animal to another. This may not be the case when the milk profile is relatively shallow.

\section{REFERENCES}

Bousquet-Melou, A., S. Bernard, M. Schneider, and P. L. Toutain. 2002. Pharmacokinetics of marbofloxacin in horses. Equine Vet. J. 34:366-372.

Carretero, M., C. Rodriguez, M. I. San Andrés, P. Forés, J. J. de Lucas, J. Nieto, S. Waxmann, M. D. San Andrés, and F. González. 2002. Pharmacokinetics of marbofloxacin in mature horses after single intravenous and intramuscular administration. Equine Vet. J. 34:360-365.

Cruz, A. D., G. C. M. Batista, J. R. Modolo, A. F. Gottschalk, and C. A. M. Lopes. 1998. Antimicrobial activity of danofloxacin and seven other drugs against Staphylococcus aureus from mastitis. Arquivo Brasileiro de Medicina Veterinaria V50 No. 4:369-373.

DANMAP. 2000:2001. Consumption of antimicrobial agents and occurrence of antimicrobial resistance in bacteria from food animals, foods and humans in Denmak. Ed. Danish Veterinary Laboratory, Copenhagen, Denmark.

DANMAP. 2000:2001. Use of antimicrobial agents and occurrence of antimicrobial resistance in bacteria from food animals, foods and humans in Denmak. Ed. Danish Veterinary Laboratory, Copenhagen, Denmark.

De Oliveira, A. P., J. L. Watts, S. A. Salmon, and F. M. Aarestrup. 2000. Antimicrobial susceptibility of Staphylococcus aureus isolated from bovine mastitis in Europe and the United States. J. Dairy Sci. 83:855-862.

Fang, W., and S. Pyörälä. 1996. Mastitis-causing Escherichia coli: Serum sensitivity and susceptibility to selected antibacterials in milk. J. Dairy Sci. 79:76-82.

Gianneechini, R. E., C. Concha, and A. Franklin. 2002. Antimicrobial susceptibility of udder pathogens isolated from dairy herds in the west littoral region of Uruguay. Acta Vet. Scand. 43:31-41.

Gibaldi, M., and D. Perrier. 1982. Pharmacokinetics. Marcel Dekker Inc, New York, NY.

Grandemange, E., and J. L. Davot. 2002. Field evaluation of the efficacy of marbofloxacin in the treatment of acute mastitis due to Gram-negative bacteria in the dairy cow. Cattle Practice 10:57-62.

Hoeben, D., E. Monfardini, C. Burvenich, and J. Hamann 2000. Treatment of acute Escherichia coli mastitis in cows with enrofloxacin: Effect on clinical signs and chemiluminescence of circulating neutrophils. J. Dairy Res. 67:485-502.

Hyatt, J. M., P. S. McKinnon, G. S. Zimmer, and J. J. Schentag. 1995. The importance of pharmacokinetic/pharmacodynamic surrogate markers to outcome. Clin. Pharmacokinetics 28:143-160.

Kaartinen, L., M. Salonen, L. Älli, and S. Pyörälä. 1995. Pharmacokinetics of enrofloxacin after single intravenous, intramuscular and subcutaneous injections in lactating cows. J. Vet. Pharmacol. Therap. 18:357-362.

Lefebvre, H. P., M. Schneider, V. Dupouy, V. Laroute, G. Costes, L. Delesalle, and P. L. Toutain. 1998. Effect of experimental renal impairment on disposition of marbofloxacin and its metabolites in the dog. J. Vet. Pharmacol. Therap. 21:453-461.

NCCLS, Document M26-A. 1999. Methods for determining bactericidal activity of antimicrobial agents.

NCCLS, Document M31-A. 1999. Performance standards for antimicrobial disk and dilution susceptibility tests for bacteria isolated from animals. 
NCCLS, Document M37-A. 1999. Development of in vitro susceptibility testing criteria and quality control parameters for veterinary antimicrobials agents.

Petracca, K., J. L. Riond, T. Graser, and M. Wanner. 1993. Pharmacokinetics of the gyrase inhibitor marbofloxacin: Influence of pregnancy and lactation in sows. J. Vet. Med. 40:73-79.

Pickerill, K. E., J. A. Paladino, and J. J. Schentag. 2000. Comparison of the fluoroquinolones based on pharmacokinetic and pharmacodynamic parameters. Pharmacotherapy 20:417-428.

Rantala, M., L. Kaartinen, E. Välimäki, M. Stryrman, M. Hiekkaranta, A. Niemi, L. Saari, and S. Pyörälä. 2002. Efficacy and pharmacokinetics of enrofloxacin and flunixin meglumine for treatment of cows with experimentally induced Escherichia coli mastitis. J. Vet. Pharmacol. Therap. 25:251-258.

Ross, D. L., and C. M. Riley 1994. Dissociation and complexation of the fluoroquinolone antimicrobials—an update. J. Pharm. Biomed. Anal. 12:1325-1331.

Salmon, S. A., J. L. Watts, F. M. Aarestrup, J. W. Pankey, and R. J. Yancey, Jr. 1998. Minimum inhibitory concentrations for selected antimicrobial agents against organisms isolated from mammary glands of dairy heifers in New Zealand and Denmark. J. Dairy Sci. 81:570-580.

Schentag, J. J. 1999. Antimicrobial action and pharmackinetics/pharmacodynamics: The use of AUIC to improve efficacy and avoid resistance. J. Chemother. 11:426-439.

Schentag, J. J., K. K. Gilliland, and J. A. Paladino. 2001. What have we learned from pharmacokinetic and pharmacodynamic theories? Clin. Infect. Dis. 32:S39-S46.

Schlegelva, J., V. Babak, E. Klimova, J. Lukasova, P. Navratilova, A. Sustackova, I. Sediva, and D. Rysanek. 2002. Prevalence and resistance to anti-microbial drugs in selected microbial species isolated from milk samples. J. Vet. Med. 49:216-225.
Schneider, M., V. Thomas, B. Boisramé, and J. Deleforge. 1996. Pharmacokinetics of marbofloxacin in dogs after oral and parenteral administration. J. Vet. Pharmacol. Therap. 19:56-61.

Shem-Tov, M., G. Ziv, A. Glickman, and A. Saran. 1997. Pharmacokinetics and penetration of marbofloxacin from blood into the milk of cows and ewes. J. Vet. Med. 44:511-519.

Shem-Tov, M., O. Rav-Hon, G. Ziv, E. Lavi, A. Glickman, and A. Saran. 1998. Pharmacokinetics and penetration of danofloxacin from the blood into the milk of cows. J. Vet. Pharmacol. Therap. $21: 209-213$

Spreng, M., J. Deleforge, V. Thomas, B. Boisramé, and H. Drugeon. 1995. Antibacterial activity of marbofloxacin, a new fluoroquinolone for veterinary use against canine and feline isolates. J. Vet. Pharmacol. Therap. 18:284-289.

Thomas, A., C. Nicolas, I. Dizier, J. Mainil, and A. Linden. 2002. In vitro antimicrobial susceptibility of mycoplasma bovis strains isolated from Belgian cattle. Proceedings from the XXII World Buiatrics Congress 2002, Hannover, Germany.

Thomas, V., J. Deleforge, and B. Boisramé. Pharmacokinetics of marbofloxacin in pre-ruminant and ruminant cattle. 1994. Pages 6061 in Proc. 6th Congr. Europ. Assoc. Vet. Pharmacol. Toxicol. Blackwell Science Ltd., Edinburgh.

Von Walser, K., B. Gandorfer, A. Steinberg, E. Treiting, and T. Winter. 1993. Untersuchungen zur antibakteriellen aktivität und pharmakokinetik von enrofloxacin $\left(\right.$ Baytril ${ }^{\circledR}$ ) bei der laktierenden kuh. Tierärztl. Umschau. 48:414-419.

Watts, J. L., S. A. Salmon, R. J. Yancey, Jr., S. C. Nickerson, L. J. Weaver, C. Holmberg, J. W. Pankey, and L. K. Fox. 1995. Antimicrobial susceptibility of microorganisms isolated from the mammary glands of dairy heifers. J. Dairy Sci. 78:1637-1648.

Waxman, S., C. Rodriguez, F. Gonzales, M. L. De Vicente, M. I. San Andres, and M. D. San Andres. 2001. Pharmacokinetic behaviour of marbofloxacin after intravenous and intramuscular administrations in adult goats. J. Vet. Pharmacol. Therapeutics 24:375-378. 